\title{
PENGEMBANGAN FRAMEWORK SISTEM INFORMASI ANTRIAN PADA STUDENT SERVICE CENTER BINUS UNIVERSITY
}

\author{
Reina; Josef Bernadi Gautama \\ Computer Science Department, School of Computer Science, Binus University \\ Jl. K.H. Syahdan No. 9, Palmerah, Jakarta Barat 11480 \\ reina@binus.edu, jbernadi@binus.edu
}

\begin{abstract}
Queues can be found in all aspects of life, especially in the service industry, including at Binus University in the Student Service Center. Sizeable number of students at certain arrival time, has led to a long queue and this affects student discomfort in waiting. Queue information systems that exist today should be developed further in order to improve the comfort of the user, such as information that is integrated with a student desk, both in seeing a queue number, and knowing the history queue. The research method used is the three phases of the Software Development Life Cycle methods Problems and Opportunities, System Requirements and System Design. The result of this research is a framework that can be used for queuing system so as to provide the freedom of time and space for the user waiting queue.
\end{abstract}

Keywords: information systems, queue, framework, service, queue

\begin{abstract}
ABSTRAK
Antrian dapat dijumpai pada semua aspek kehidupan terutama dalam industri jasa, termasuk di BINUS University pada Student Service Center. Jumlah mahasiswa yang cukup besar pada waktu kedatangan tertentu, telah menyebabkan sebuah antrian yang cukup lama dan hal ini berdampak pada ketidaknyamanan mahasiswa dalam menunggu. Sistem informasi antrian yang ada saat ini perlu dikembangkan lebih lanjut agar dapat meningkatkan kenyamanan pengguna, seperti mendapatkan informasi yang terintegrasi dengan student desk, baik dalam melihat nomor antrian, maupun mengetahui history antrian. Metode penelitian yang digunakan adalah tiga tahapan dari metode Software Development Life Cycle Problem \& Opportunities, System Requirements dan System Design. Hasil penelitian ini berupa framework yang dapat digunakan untuk sistem antrian sehingga memberikan kebebasan waktu dan ruang tunggu bagi pengguna antrian.
\end{abstract}

Kata kunci: sistem informasi, antrian, framework, service, queue 


\section{PENDAHULUAN}

Industri pendidikan merupakan bagian dari industri sektor jasa di mana pada sektor jasa, promosi yang paling efektif adalah rekomendasi dari pelanggan atas kepuasan dari layanan yang diterima pada saat bertransaksi maupun layanan setelah transaksi dilakukan (Reina, 2012). BINUS University sebagai institusi pendidikan senantiasa memperhatikan dan meningkatkan kualitas layanan yang diberikan baik kepada calon mahasiswa, mahasiswa, orang tua, dan dosen. Salah satu bentuk layanan yang diberikan adalah menyediakan one stop service yang dikenal dengan istilah Student Service Center. Konsep layanan ini mengadopsi model layanan yang berkembang saat ini, yaitu mengutamakan kenyamanan, keakuratan data dan informasi. Untuk menunjang kenyamanan, mahasiswa dilayani oleh staf secara personal dengan fasilitas front desk, ruang tunggu yang dilengkapi oleh kursi tunggu yang nyaman, LCD TV berisi informasi dan hiburan, serta sistem informasi antrian. Untuk menunjang keakuratan data dan informasi, staf dibantu oleh sistem informasi dengan data yang sudah terintegrasi.

Student Service Center pada BINUS University terdiri dari layanan mahasiswa dan layanan keuangan mahasiswa. Layanan mahasiswa memberikan layanan informasi terkait dengan regulasi, prosedur, dan sistem yang berlaku pada BINUS University serta melayani pengambilan dan penyerahan berkas seperti surat keterangan yang dibutuhkan mahasiswa, berkas kelulusan dan sebagainya. Layanan keuangan mahasiswa memberikan layanan terkait dengan informasi keuangan, pembayaran biaya yang tidak termasuk uang kuliah dan sebagainya. Dengan memanfaatkan sistem informasi yang sudah ada, history pertanyaan dan jawaban yang diberikan dapat disimpan, sehingga mempermudah staf Student Service Center dalam menganalisa kebutuhan mahasiswa.

Sistem informasi antrian yang diterapkan saat ini, dikembangkan pada tahun 2009. Sejak diimplementasi di tahun 2009, belum pernah ada pengembangan lebih lanjut seperti penambahan fitur dan integrasi dengan student desk yang digunakan oleh mahasiswa. Pada periode tertentu, antrian di Student Service Center mengalami lonjakan yang cukup signifikan. Seperti pada periode pengumpulan laporan kerja praktek, skripsi/tugas akhir, pengambilan berkas kelulusan, persiapan awal kuliah, keterlambatan pembayaran dan sebagainya. Lonjakan ini dapat mengakibatkan berkurangnya kenyamanan fasilitas ruang tunggu yang disediakan oleh Student Service Center bagi mahasiswa. Pelanggan menilai waktunya cukup berharga, sehingga mereka tidak mau membuang waktu yang lama untuk mendapatkan layanan (Iswiyanti \& Siringoringo, 2004). Untuk mengatasi terbuangnya waktu menunggu mahasiswa, maka perlu dilakukan penelitian pengembangan framework yang dapat dilakukan pada sistem informasi antrian.

Adapun tujuan dari penelitian ini untuk mengembangkan framework sistem informasi antrian pada Student Service Center BINUS University. Manfaat yang diperoleh dari penelitian ini adalah sebagai model dalam merancang dan implementasi sistem antrian. Manfaat lain yang dapat diperoleh adalah sebagai masukan bagi pengembangan sistem informasi antrian lebih lanjut untuk mengatasi terbuangnya waktu menunggu mahasiswa dan meningkatkan layanan kepada pengguna. Sistem antrian mencakup pelanggan yang datang dengan laju konstan atau bervariasi untuk mendapatkan layanan pada suatu fasilitas layanan. Jika pelanggan yang datang dapat memasuki fasilitas layanan, pelanggan dapat langsung dilayani. Jika pelanggan harus menunggu dilayani, pelanggan berpartisipasi atau membentuk antrian, dan akan berada dalam antrian hingga pelanggan dapat giliran untuk dilayani (Antono, 2010).

Tidak dapat dipungkiri bahwa menunggu adalah pekerjaan paling membosankan dan memakan waktu yang tidak dapat diprediksi. Situasi menunggu juga merupakan bagian dari keadaan yang terjadi dalam rangkaian kegiatan operasional yang bersifat random dalam suatu fasilitas pelayanan (Ikrimah, Supriyono, dan Kharisudin, 2012). Dalam tulisan Rafaeli (Rafaeli, 2002), menunggu dapat mempengaruhi emosi dari seseorang, karena membuang waktu, dan biaya. Pelanggan 
yang tidak suka menunggu dapat memberikan kesan buruk atas kualiatas layanan yang diberikan oleh organisasi. Menunggu dapat dikaitkan dengan beberapa sikap, seperti merasa tidak dibantu saat dalam kondisi darurat tanpa ada kepastian kapan dilayani dan kualitas layanan yang akan diterima.

Hasil dari penelitian ini diharapkan dapat membantu meningkatkan pelayanan kepada para pengguna antrian, sehingga waktu tunggu para pengguna antrian dapat dimanfaatkan untuk kegiatan lainnya.

\section{METODE}

Metode penelitian yang digunakan dalam penelitian ini menggunakan tiga tahap pertama yang ada pada metode SDLC (Software Development Life Cycle) yaitu Problem \& Opportunities, System Requirements, System Design.

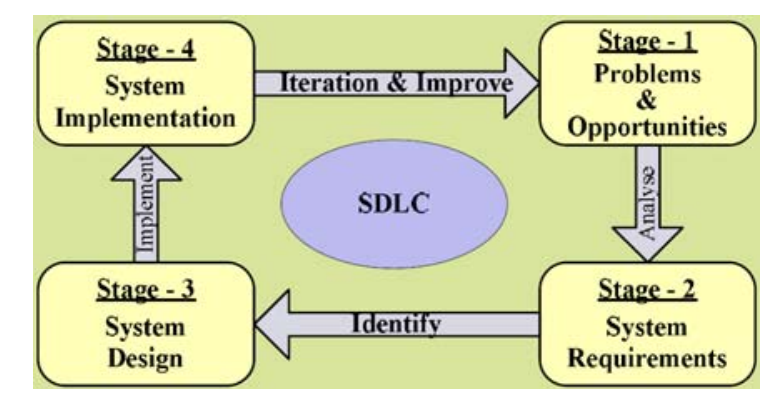

Gambar 1 Model penelitian SDLC (Al-Zahrani, 2006)

Gambar 1 menunjukan kerangka pikir yang digunakan dalam penelitian ini. (1) Problem \& Opportunities - Melakukan analisa sistem informasi antrian yang telah diimplementasi pada Student Service Center BINUS University melalui observasi lapangan. (2) System Requirements - Melakukan identifikasi masalah yang ada pada sistem yang berjalan dan melakukan survei dengan menyebar kuesioner kepada pengguna sistem informasi antrian saat ini. Berdasarkan histori kedatangan mahasiswa di tahun 2012, tercatat sebanyak 101.412 mahasiswa, sehingga rata-rata kedatangan per bulan sebesar 8.451. Mengambil jumlah sampel sebanyak 5\% dari populasi, maka ditargetkan 434 kuesioner mahasiswa yang disebar dalam kurun waktu dua bulan kepada mahasiswa yang datang ke Student Service Center. Survei dilakukan pada bulan Juni dan Juli 2013. Data diolah untuk mendapatkan kebutuhan pengembangan dari sistem yang telah ada. (3) System Design Mengembangkan framework sistem informasi antrian.

\section{HASIL DAN PEMBAHASAN}

\section{Existing System}

Sistem antrian yang berjalan mencatat waktu kedatangan mahasiswa, waktu mulai layanan, dan waktu selesai layanan. Waktu kedatangan mahasiswa dicatat pada saat mahasiswa melakukan tapping BINUSIAN Card Flazz pada RFID Reader dan memilih kategori layanan yang dibutuhkan. Sistem akan memberikan informasi nomor antrian dan sisa jumlah antrian sesuai dengan kategori layanan yang dipilih. Data nomor antrian, jurusan, NIM, dan nama mahasiswa yang belum terlayani 
dapat dilihat oleh staf front liners. Sistem secara otomatis akan menampilan nomor counter, nomor antrian dan nama mahasiswa yang akan dilayani sesuai dengan urutan kedatangan pada LCD TV yang tersedia. Setelah mahasiswa tiba pada counter yang dituju, maka staf akan memulai layanan dengan menekan tombol Start Layanan. Pada saat tombol ditekan, maka saat itu pula waktu mulai layanan dicatat. Setelah selesai melayani, maka staf akan mencatat informasi layanan yang diberikan dan menekan tombol Simpan. Pada saat tombol Simpan ditekan, maka waktu selesai layanan dicatat oleh sistem. Waktu tunggu mahasiswa adalah selisih waktu mulai layanan dengan waktu kedatangan. Gambar 2 menunjukkan sistem antrian yang berjalan saat ini.

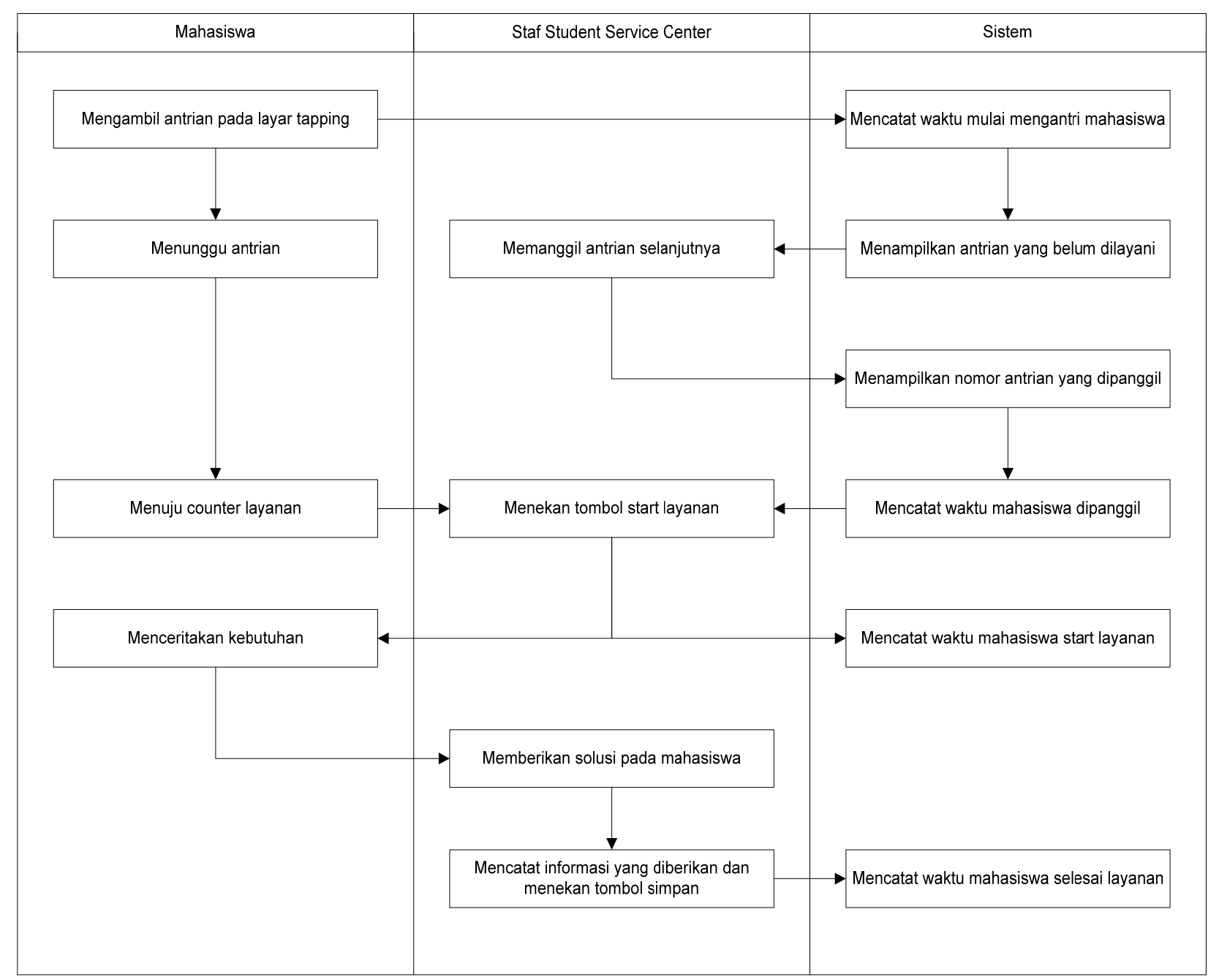

Gambar 2 Sistem Antrian Student Service Center

\section{Problem Identification}

Student Service Center memiliki delapan counter front desk untuk melayani mahasiswa. Pada periode tertentu seperti batas waktu pengumpulan laporan, periode pengambilan berkas, periode registrasi perkuliahan, jumlah mahasiswa yang datang untuk dilayani mengalami lonjakan, sedangkan jumlah counter tidak dapat bertambah secara fleksibel. Hal ini menyebabkan meningkatkannya jumlah mahasiswa yang berada pada antrian dan dengan ruang tunggu yang terbatas, mengakibatkan berkurangnya kenyamaan dalam menunggu. 


\section{Survey}

Untuk mendapatkan informasi terkait dengan fasilitas saat menunggu, waktu tunggu, dan fleksibilitas ruang tunggu, maka dilakukan survei kepada mahasiswa yang datang ke Student Service Center. Survei dilakukan dengan penyebaran kuesioner pada bulan Juni s.d. Juli 2013. Bentuk kuesioner yang disebar adalah sebagai berikut:

\section{Kuesioner Sistem Antrian di Student Service Center}

Petunjuk Pengi sian :

Berilah tanda silang (o pada kotak ja waban di bawah ini yang sesuai pendapat anda

SS = Sangat Setıij L; S = Setuju; TS = Tidak Setuj Ll; STS = Sangat Tidak Setuju

\begin{tabular}{|l|c|c|c|c|}
\hline \multicolumn{1}{|c|}{ Pertanyaan } & SS & S & TS & STS \\
\hline Saya sering membutuhkan layanan di student service center & & & & \\
\hline Fasilitas ruang tunggu yang diberikan sudah baik & & & & \\
\hline Saya menyukai tayangan hiburan di student service center & & & & \\
\hline Saya menyukai tempat menuggu di student service center & & & & \\
\hline Menunggu di student service center tidak membosankan & & & & \\
\hline Jika memungkinkan saya menunggu tidak di ruang student servicecenter & & & & \\
\hline $\begin{array}{l}\text { Saya seharusnya dapat mem anfa atkan waktu menunggu di student service } \\
\text { center bersamaan dengan melakukan kegiatan lain }\end{array}$ & & & & \\
\hline
\end{tabular}

Tuliskan saran anda untuk pengembangan sistem antrian di student service center:

Tuliskan saran anda untuk pengembangan fasilitas di ruang tunggu student serwice center:

Pertanyan seputar registrasi dan perkuliahan dapat disampaikan melalui binusmapa menu Services $\Rightarrow$ Student $\Rightarrow$ Contact Us

***: Terimakasih telah mengisi kuesioner ini ***

Gambar 3 Kuesioner Sistem Antrian di Student Service Center

Dari target kuesioner sebanyak 434, berhasil diperoleh sebanyak 495 kuesioner valid dari 500 kuesioner yang disebar. Hasil survei dari setiap butir pertanyaan dapat dilihat pada gambar 4 s.d. gambar 10 .

Saya sering membutuhkan layanan

distudent service center

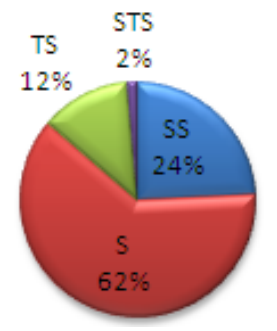

Gambar 4 Pertanyaan pertama

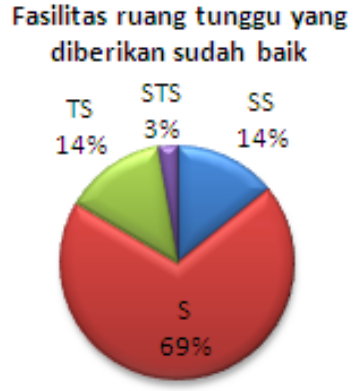

Gambar 5 Pertanyaan kedua 
Saya menyukai tayangan hiburan di student service center

STS SS

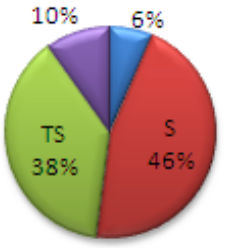

Gambar 6 Pertanyaan ketiga

Menunggu di student service center tidak membosankan

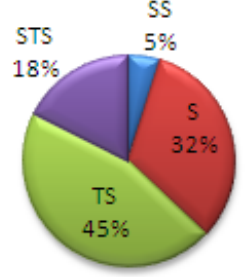

Gambar 8 Pertanyaan kelima
Saya menyukai tempat menuggu di student service center

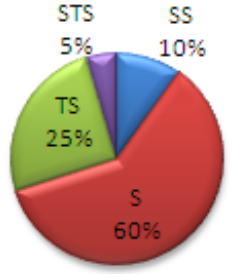

Gambar 7 Pertanyaan keempat

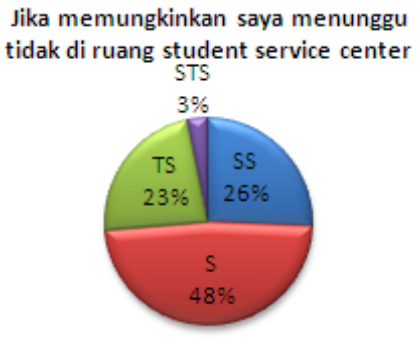

Gambar 9 Pertanyaan keenam

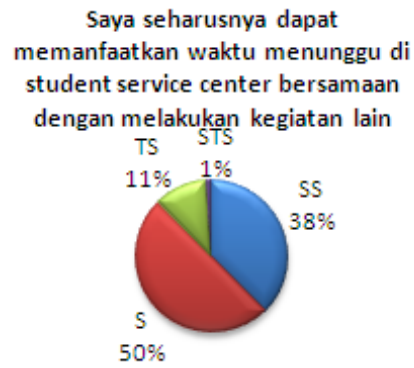

Gambar 10 Pertanyaan ketujuh

Pengelompokkan hasil survei yang mempengaruhi waktu tunggu, fleksibilitas ruang tunggu, dan fasilitas saat menunggu dapat dilihat pada tabel kelompok hasil survei.

Tabel 1 Kelompok Hasil Survei

\begin{tabular}{lccccc}
\hline \multicolumn{1}{c}{ Pertanyaan } & SS & S & TS & STS & Kelompok \\
\hline $\begin{array}{l}\text { Fasilitas ruang tunggu yang diberikan sudah baik } \\
\text { Saya menyukai tayangan hiburan di student service } \\
\text { center }\end{array}$ & $14 \%$ & $69 \%$ & $14 \%$ & $3 \%$ & Fasilitas \\
$\begin{array}{l}\text { Saya menyukai tempat menuggu di student service } \\
\text { center }\end{array}$ & $10 \%$ & $60 \%$ & $25 \%$ & $5 \%$ & Fasilitas \\
$\begin{array}{l}\text { Saya sering membutuhkan layanan di student service } \\
\text { center }\end{array}$ & $24 \%$ & $62 \%$ & $12 \%$ & $2 \%$ & Waktu Tunggu \\
$\begin{array}{l}\text { Menunggu di student service center tidak } \\
\text { membosankan }\end{array}$ & $5 \%$ & $32 \%$ & $45 \%$ & $18 \%$ & Waktu Tunggu \\
$\begin{array}{l}\text { Jika memungkinkan saya menunggu tidak di ruang } \\
\text { student service center }\end{array}$ & $26 \%$ & $48 \%$ & $23 \%$ & $3 \%$ & Fleksibilitas \\
$\begin{array}{l}\text { Saya seharusnya dapat memanfaatkan waktu menunggu } \\
\text { di student service center bersamaan dengan melakukan } \\
\text { kegiatan lain }\end{array}$ & $38 \%$ & $50 \%$ & $11 \%$ & $1 \%$ & Fleksibilitas \\
\hline
\end{tabular}


Sebanyak total $83 \%$ responden menjawab sangat setuju dan setuju bahwa fasilitas ruang tunggu yang diberikan sudah baik. Sebanyak total 52\% responden menjawab sangat setuju dan setuju bahwa tayangan hiburan yang ditayangkan melalui LCD TV sudah disukai. Sebanyak total $70 \%$ responden menjawab sangat setuju dan setuju bahwa mereka menyukai tempat menunggu di Student Service Center. Dari kelompok pertanyaan yang mempengaruhi fasilitas Student Service Center didapat lebih dari 50\% responden menyatakan fasilitas ruang tunggu, tayangan hiburan, tempat menunggu sudah memadai dan baik.

Sebanyak total $86 \%$ responden menjawab sangat setuju dan setuju sering membutuhkan layanan di Student Service Center, hal ini menunjukkan tingkat kebutuhan layanan cukup tinggi. Sebanyak total $73 \%$ responden menjawab tidak setuju dan sangat tidak setuju bahwa menunggu di Student Service Center tidak membosankan, hal ini menunjukkan adanya kebosanan pada saat menunggu. Sehingga dari kelompok pertanyaan yang mempengaruhi waktu tunggu dapat disimpulkan bahwa dibutuhkan sistem antrian yang dapat mengatasi rasa bosan atau jenuh pada saat menunggu walaupun fasilitas yang diberikan sudah dinilai baik.

Sebanyak total $74 \%$ responden menjawab sangat setuju dan setuju bahwa mereka berharap dapat menunggu tidak di ruang Student Service Center, hal ini menunjukkan bahwa mereka membutuhkan fleksibilitas ruang tunggu yang tidak harus terpaku di ruang Student Service Center. Sebanyak total $88 \%$ responden menjawab sangat setuju dan setuju bahwa mereka dapat memanfaatkan waktu menunggu untuk kegiatan lainnya. Sehingga dari kelompok pertanyaan yang mempengaruhi fleksibilitas dalam menunggu dapat disimpulkan bahwa dibutuhkan sistem antrian yang dapat memberikan kebebasan ruang tunggu dan kebebasan dalam melakukan kegiatan lain saat menunggu antrian.

\section{Proposed Design}

Berdasarkan analisa sistem yang berjalan, identifikasi masalah yang ditemui, dan analisa hasil survei, maka perlu dikembangkan sistem antrian yang dapat memberikan kebebasan ruang tunggu dan kebebasan dalam melakukan kegiatan lain saat mengantri. Dengan memanfaatkan portal Binusmaya yang dimiliki setiap mahasiswa, dan dapat di akses dengan media internet, dapat dikembangkan perluasan layar antrian seperti yang ditampilkan pada gambar 11, sehingga mahasiswa dapat memantau antrian melalui website ini.

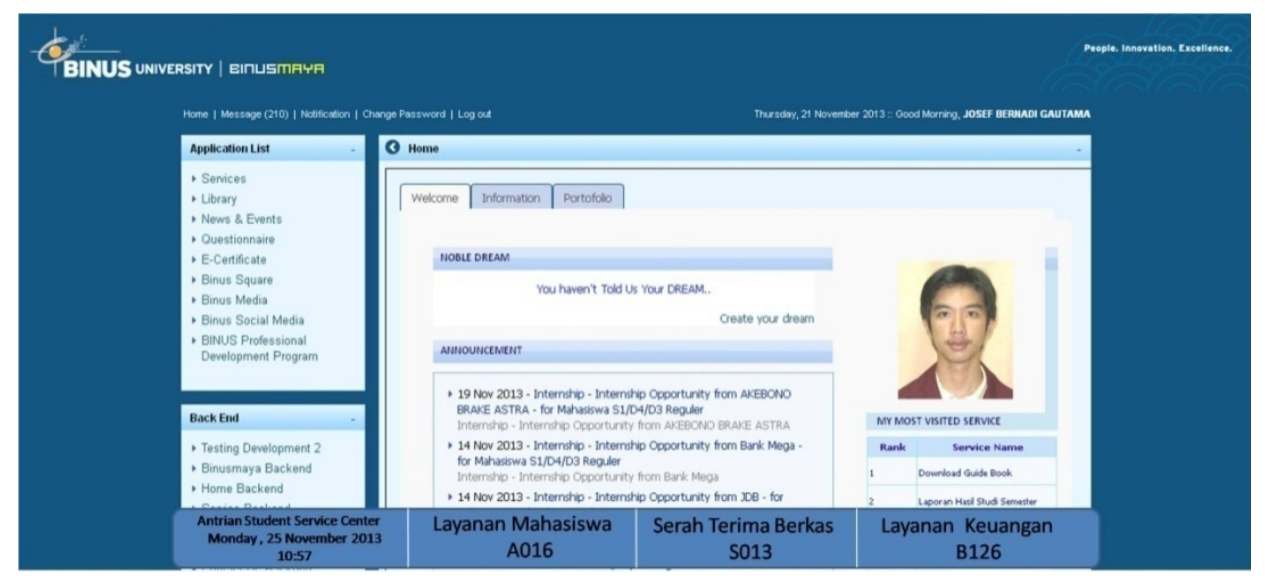

Gambar 11 Rancangan Antrian pada Binusmaya 


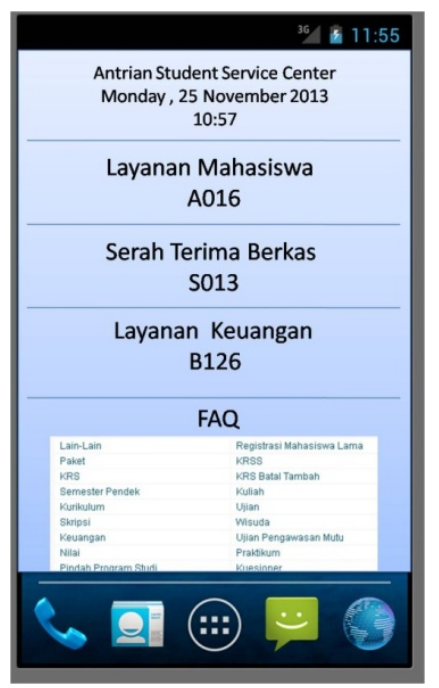

Gambar 12 Rancangan Antrian pada Smartphone

Gambar 12 menunjukan rancangan aplikasi pada smartphone untuk menampilkan antrian yang sedang berlangsung secara realtime. Pada bagian bawah layar ditampilkan juga FAQ, yang berisi pertanyaan umum yang sering ditanyakan oleh mahasiswa. Dengan adanya FAQ ini diharapkan mahasiswa yang sedang menunggu dapat mencari jawaban atas pertanyaannya pada FAQ.

\section{SIMPULAN}

Dari hasil yang didapat, maka dapat disimpulkan bahwa adanya kebutuhan sistem antrian untuk mengatasi rasa bosan, kebebasan ruang tunggu dan kebebasan dalam melakukan kegiatan lain saat menunggu antrian pada Student Service Center. Dengan aplikasi antrian, antrian yang sedang berjalan dapat dipantau dari jarak jauh melalui media online, sehingga kebutuhan kebebasan ruang tunggu dan kebebasan dalam melakukan kegiatan lain dapat dipenuhi. Hasil perancangan ini disarankan untuk dikembangkan lebih lanjut agar dapat diimplementasi dengan baik. Penelitian ini dapat dikembangkan ke penelitian selanjutnya agar fitur-fitur yang ditawarkan lebih memadai untuk meningkatkan kenyamanan dalam menunggu.

\section{DAFTAR PUSTAKA}

Al-Zahrani, S. 2006. An Information Management System Model for the Industrial Incidents in. Journal of Computer Science 2, 447-454

Antono, S. D. 2010. Penerapan Model Simulasi pada Antrian di Bagian Pengobatan Puskesmas Prambon Kabupaten Jeruk Nganju. Jurnal Penelitian Kesehatan Suara Flores, 1(4).

Ikrimah, A., Supriyono, Kharisudin, I. (2012). Analisis Antrian Single Channel Singel Phase Pada Loket Penjualan Tiket Kereta Api Kaligung di Stasiun Poncol. UNNES Journal of Mathematics. UJM, 1 (1). 
Iswiyanti, A. S., Siringoringo, H. (2004). Analisis Antrian Loket Karcis Taman Margasatwa Ragunan DKI Jakarta. Majalah Ekonomi dan Komputer, 3(XII).

Rafaeli, A., Barron, G., Haber, K. (2002). The Effects of Queue Structure on Attitudes. Journal of Service Research, 5, 125.

Reina. (2012). Faktor-Faktor yang Mempengaruhi Kepuasan Mahasiswa Pada Universitas Bina Nusantara. Binus Business Review, 563-572. 